\title{
Nondestructive Imaging of Cellular Solid Foods
}

\section{Alam, Syed Ariful}

Springer International Publishing AG

2016-01-01

Alam , S A \& Sozer , N 2016 , Nondestructive Imaging of Cellular Solid Foods . in N Sozer (ed.) , Imaging Technologies and Data Processing for Food Engineers . Food Engineering Series , Springer International Publishing AG , Cham , pp. 169-196 . https://doi.org/10.1007/978-3-319-24735-9_6

http://hdl.handle.net/10138/164034

https://doi.org/10.1007/978-3-319-24735-9_6

submittedVersion

Downloaded from Helda, University of Helsinki institutional repository.

This is an electronic reprint of the original article.

This reprint may differ from the original in pagination and typographic detail.

Please cite the original version. 


\title{
Chapter 6 \\ Nondestructive Imaging of Cellular Solid Foods
}

\author{
Syed Ariful Alam and Nesli Sozer
}

\subsection{Introduction}

Food structure is an important quality-related parameter which has a direct impact on perceived texture; influenced by ingredients, their interaction, processing and storage history. Recent innovations in food imaging technologies or novel labelling strategies opens up new opportunities in the field of food technology to understand the food processing-structure-property-sensory relationship. To determine the food microstructure, several methods are used in food sector such as ultrasound, magnetic resonance imaging (MRI), stereomicroscopy, computer vision technique, digital imaging using charge coupled device (CCD) sensor, thermal imaging, flatbed scanning, radiography and most recently XMT. Most of the microscopy techniques is destructive and require sample preparation or treatments which would ultimately cause structural changes. Destructive imaging methods are usually time consuming and require costly instrumentation which runs with sophisticated software, therefore, not suitable to be used for "on-line" quality control tool. These techniques cannot provide accurate information on cell distribution, average cell wall thickness and interconnection between cells which are the most important microstructural features of open and solid cereal foams (Trater et al. 2005). It is also difficult to obtain adequate contrast between void and solid phase by scanning electron microscopy (SEM) and with optical imaging due to improper lightening and angle of illumination. Moreover, in these methods, algorithms such as Fourier transformation used for segmentation (combination of image subtraction and edge

S. A. Alam $(\bowtie)$

University of Helsinki, Helsinki, Finland

e-mail: ariful.alam@vtt.fi

S. A. Alam · N. Sozer

VTT Technical Research Centre of Finland, Espoo, Finland

N. Sozer

e-mail: nesli.sozer@vtt.fi

(C) Springer International Publishing Switzerland 2016 

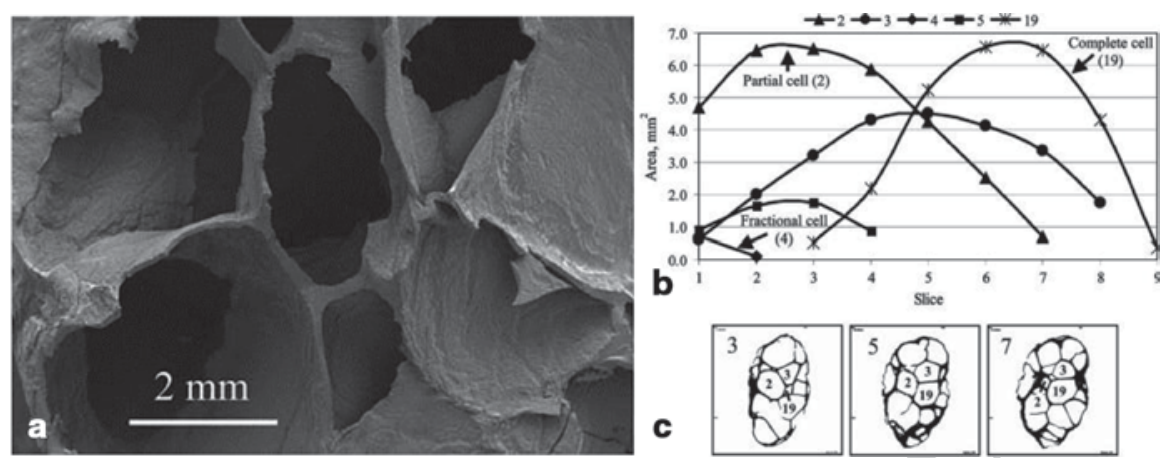

Fig. 6.1 a Scanning electron micrograph (SEM) image of extrudates of $5 \%$ whey protein isolate (WPC) processed at 26\% feed moisture. b Development of cells 2, 3, 4, 5 and 19 over slices $1-9$. c The appearance of cross section of the cells 2, 3 and 19 in the slices 3,5 and 7 is shown in 2D XMT images of extrudate processed with same recipe and process condition. (Adapted with permission from Trater et al. (2005))

detection to distinguish void and solid phase), which require large computational time and also might give computational error and thus lead to inaccurate results (Trater et al. 2005).

Cross-sectional area of air cells changes in a cellular solid matrix when depth of slice within the volume of interest (VOI) increases (6.1). The cells can be categorized into three groups: complete, partial or fractional cells according to their gradual development. Depth of slice had a significant effect on the cell area distribution pattern which was clearly shown in the XMT image where typical 2D imaging such as SEM is unable to characterize the distribution of actual 3D cell size distribution.

Due to the depth focus and high contrast between void and solid phase, XMT images were much better than SEM images. In SEM, sample preparation needs physical cutting which cause partial damage and initiate crack through the pores. Multiple 2D images of the cross section facilitate imaging tremendously with incremental depth. Figure 6.1 demonstrates how cross-sectional area of air cells changes within the VOI of different consecutive slices in the form of complete, partial or fractional cells. It is clear that there is significant change in the cell-area distribution within the depth of cells. Traditional imaging tools such as SEM and light microscopy are unable to characterize accurate $3 \mathrm{D}$ cell area distribution of the extruded foams. However, the presence of partial and fractional cells within the VOI gives inaccurate results thus corrections are needed. After correction, although the trends are similar, estimates of cell size (average cell diameter and weighted average cell diameter) were $12 \%$ larger. Similar trends observed for all parameters except open wall area ratio and weighted open wall area ratio, when processing corrections are made (Trater et al. 2005).

X-ray imaging or radiography should not be confused with XMT as radiography mostly used for determination of internal quality (i.e. internal damage or, volume of different internal features) of agricultural products such as nuts, fruits and grains (Kotwaliwale et al. 2010). In this method, high-energy X-ray beam penetrates into 
the test product. Depending on the food composition, properties and internal structure, photons of X-ray beam distributed in different ways: (1) transmitted, (2) scattered and (3) absorbed. The transmitted X-ray beams later create visual contrast in the images showing the differences of test objects (Kotwaliwale et al. 2010).

XMT is one of the nondestructive techniques that would enable to visualize and characterize the internal structural architecture, porosity, cell wall thickness and cell diameter of processed cellular solid foods such as bread, extruded snacks, biscuits and cakes (Kotwaliwale et al. 2010). XMT enables to develop three-dimensional (3D) images of various food structures by combining 2D images with the help of dedicated software and programmes which would facilitate visualization and quantitative measurement without chemical fixation or tedious and time-consuming sample preparation protocols (Kiani and Sun 2011). MRI is another useful imaging technique which is capable to produce images through the proton mobility in foods using static magnetic fields and radio frequencies. The intensity of MRI signals originates from the water, fat or even from sugars present within the food matrix and allows accurate prediction of these components on structure at various timetemperature conditions. MRI has potential to determine several quality attributes such as presence of voids or foreign objects, internal damage caused by insects and larvae, dry/wet regions within test food, state of maturity and bruises, for example, in fruits and vegetables (Kotwaliwale et al.2010). MRI requires complex and expensive system as it has certain material restrictions with high investment and operating costs (Kiani and Sun 2011). Special sample preparation is needed for both negative and positive imaging with MRI. A major advantage of XMT over MRI is the good spatial resolution which could be reached without using extensive sample preparation with statistically similar results (Horvat et al. 2014).

However, both MRI and XMT imaging methods are unable to represent optical properties; therefore, a correlation needs to be set between different features such as greyness and pixel bunches (2D) or voxels (3D). Although 2D image analysis is fast and relatively easy technique compared to 3D image analysis, image analysis of cereal solid foams need third orthogonal dimension to produce high-quality images representing proper structure of air cells and thus able to represent original size and shape of the cellular structure including cell size distribution, average cell wall thickness, average cell diameter and connectivity of cells through the quantitate analysis of projection data (Sozer et al. 2011).

The interconnected pores can be segmented by watershed algorithm in order to accurately evaluate the pore sizes and shapes (Plews et al. 2009). The technique can be used to analyse samples with inhomogeneous porosity where pore size was based on volume fraction and aperture size was based on area fraction. The algorithm itself is an efficient tool for closing open cells to obtain pore size distributions as well as interconnecting pore aperture distributions (Plews et al. 2009). Average cell wall thickness and apparent pore size distribution can be obtained from $2 \mathrm{D}$ image analysis, although it is challenging to get accurate information about pore connectivity. Combined 2D and 3D analyses gives a thorough characterization of the porous food structure provided that they have sufficient density difference throughout the matrix. 
Cell volume and cell connectedness of white bread and extrudates have been analysed by gas pycnometry (Bhatnagar and Hanna 1996; Hicsasmaz and Clayton 1992; Jones et al. 2000). The technique is an indirect method which utilizes the ideal gas law to determine the true volume of a solid. The method is weak as some closed adjoining cells could be considered as interconnected cells though they are not actually connected. Small cracks within the cell wall may allow gas to penetrate through the solid matrices surrounding the air cells but also applied pressure during the measurements can further cause cracks depending on sample type (Trater et al. 2005).

The cellular structure of solid cereal foams such as bread, cake, extruded snacks and biscuits has an effect on textural properties such as hardness, chewiness or crispiness based on product category. Sensory quality of baked and extruded cereal foods are strongly dependent on the structural architectures such as air cell size, shape and their distribution within the food matrix; therefore, it is important to evaluate these structural parameters to aid product design and optimize processing conditions (Sozer et al. 2011b).

\subsection{X-Ray Microtomography for Foods}

Basic principles of imaging by XMT rely on material density, atomic number and on X-ray absorption capacity (Babin et al. 2007). X-ray microtomography (XMT) is becoming an important tool for food microstructure analysis due to the high penetrating power, probing efficiency and noninvasive characteristics. However, as in the case of most imaging technologies benchtop XMT equipment might produce image artefacts which require special data handling procedures. When a polychromatic beam used in X-ray equipment a strong artefact appear known as "cupping effect" caused by beam hardening (Vidal et al. 2005). The fact is that when heterogeneous (combination of low- and high-energy photon) beam pass through an object the lower energy photon absorbed more readily and results in attenuated beam with higher average energy. Therefore, the longer the exposure time of the object to the X-ray radiation, the harder the X-ray become. The centre of the test sample usually exposed to the radiation longer period of time compared to the edges thus may appear less absorbent during reconstruction. However, pre-hardening of the $\mathrm{X}$-ray beam by placing a filter between the X-ray source and test sample could help to reduce the cupping effect (Barigou et al. 2013). The "hot points" artefact usually appears after image reconstruction stage. If the photons hit the CCD camera after passing through the scintillator this results in hot points which are recognized by streaks or thin line throughout the sample volume (Barigou et al. 2013). On the other hand, dead pixels in the CCD camera may also cause a common artefact named "ring artefacts", which appear when the detector response and the light intensity are not linearly proportional. This artefact is generally tackled by the XMT software. Besides the aforementioned artefacts, varying output of X-ray sources, sensitivity of the detector, nonuniform voltage supply, incomplete viewing and scattering of photons are reported to cause also artefacts (Vidal et al. 2005). 
In desktop-based XMT, X-rays are generated by accelerating the electrons in a strong electric field through the collision of electrons from a cathode (source of electron) to anode (metallic target such tungsten block on a copper support). After collision, some electrons achieve higher energy than others and consequently knock out the electrons of lower energy from the inner shells of the target atoms. The higher energy electron fills up the vacant place and produce X-rays (Betz et al. 2007). Although desktop-based XMT can produce good-quality image from micron to submicron level, synchrotron-based XMT may perform well below $5 \mu \mathrm{m}$ spatial resolution. Higher resolution and lower acquisition time makes synchrotron superior over desktop-based XMT. Samples can be imaged within a short period of time due to the wide energy range (4-200 keV) of synchrotron facility. Higher photon flux allows imaging with very narrow range $\left(\Delta \mathrm{E} / \mathrm{E} \rightarrow 10^{-2}-10^{-4}\right)$ and advantageous for both quantitative absorption and phase contrast (Betz et al. 2007).

Detailed comparison between synchrotron and commonly uséd desktop-based XMT is summarized in Table 6.1 and their assembly and working principles are shown in Fig. 6.2.

\subsection{Image Processing and Data Handling}

The device for XMT imaging system consists of an X-ray source (mono or polychromatic), stage (fixed or rotational) containing sample holder and an X-ray detector. The X-ray detector transforms X-rays into visible light and transferred through optical lenses to CCD camera (Chaunier et al. 2007).

The energy decrease during exposure of a test sample to X-ray beam is called as attenuation. Attenuation coefficient is the term which describes how easily an $\mathrm{X}$-ray beam will penetrate through a test sample, when exposed. The sample which is transparent to the X-ray beam showed small attenuation coefficient, on the other hand, large coefficient is the indicator of dense material. The intensity of colliding photons exponentially reduces and directly related to the energy of the X-ray beam which is represented by Eq. 6.1 (Curry et al. 1990).

$$
I=I_{0} e^{-\mu_{\mathrm{m}} Z \rho}
$$

where $I=$ intensity of photons through the matter, $\mu_{\mathrm{m}}=$ mass attenuation coefficient, (in $\left.\mathrm{mm}^{2} \mathrm{~g}^{-1}\left(\mathrm{M}^{-1} \mathrm{~L}^{2}\right)\right), \mathrm{z}$ the thickness of the matter (in mm (L)) and $\rho$ is the material density (in $\mathrm{g} \mathrm{mm}^{-3}\left(\mathrm{M} \mathrm{L}^{-3}\right)$ ).

The absorption of X-rays is different for different material depending on the material density, which is expressed as X-ray computed tomography (CT) number. In $\mathrm{XMT}$ analysis, the test material is exposed by X-rays from a specific direction emitted from X-ray source. The intensities of attenuated X-rays after passing through a test object are measured by a detector followed by digitization give a digital image after reconstruction using CT numbers. The CT number depends on the linear attenuation coefficient which is further expressed by the brightness data of the obtained image. The CT number is defined as follows (Eq. 6.2): 
Table 6.1 Comparison of synchrotron-based XMT and desktop XMT. (Betz et al. (2007); Mamlouk and Guessasma (2013); Kotwaliwale et al. (2014))

\begin{tabular}{|c|c|}
\hline Synchrotron-based XMT & Desktop-based XMT \\
\hline $\begin{array}{l}\text { Monochromatic X-rays in a parallel beam } \\
\text { geometry }\end{array}$ & $\begin{array}{l}\text { Polychromatic X-rays operate with cone- } \\
\text { geometry using raw spectrum from X-ray } \\
\text { source }\end{array}$ \\
\hline Higher resolution and lower acquisition time & $\begin{array}{l}\text { Comparatively low resolution and high acqui- } \\
\text { sition time }\end{array}$ \\
\hline 10-100 times faster & Comparatively lower \\
\hline $\begin{array}{l}\text { Lower construction error to build 3D image } \\
\text { due to the use of filter-back projection algo- } \\
\text { rithm for volume construction }\end{array}$ & $\begin{array}{l}\text { Cone-beam construction method used which } \\
\text { give high construction error, errors increase } \\
\text { with distance from the central slice }\end{array}$ \\
\hline $\begin{array}{l}\text { Samples can be analysed at submicron level. } \\
\text { Samples below } 5 \mu \mathrm{m} \text { spatial resolution usually } \\
\text { analysed using synchrotron }\end{array}$ & $\begin{array}{l}\text { Not suitable for below } 5 \mu \mathrm{m} \text { spatial resolution, } \\
\text { gives blurry } 3 \mathrm{D} \text { images }\end{array}$ \\
\hline Better resolution due to homogeneous signal & Lower resolution due to heterogeneous signal \\
\hline $\begin{array}{l}\text { Use of monochromatic source allows the } \\
\text { selection of specific X-ray energy suitable for } \\
\text { analysis }\end{array}$ & $\begin{array}{l}\text { Selection of X-ray energy is not possible due } \\
\text { to the use of polychromatic source }\end{array}$ \\
\hline $\begin{array}{l}\text { Smaller beam size restricts to use for small } \\
\text { sample, if the dimension of the sample being } \\
\text { equivalent to the beam size, this method is not } \\
\text { suitable }\end{array}$ & $\begin{array}{l}\text { Large beam size facilitate the use for large } \\
\text { sample }\end{array}$ \\
\hline Improved qualitative and quantitative analysis & $\begin{array}{l}\text { Still good enough and comparable with the } \\
\text { quality of synchrotron }\end{array}$ \\
\hline $\begin{array}{l}\text { High-resolution images with higher pixels but } \\
\text { requires large storage capacity }\end{array}$ & $\begin{array}{l}\text { Comparatively low-resolution images with } \\
\text { low pixel density thus suitable for small stor- } \\
\text { age capacity }\end{array}$ \\
\hline $\begin{array}{l}\text { Use of filter-back projection algorithms for } 3 \mathrm{D} \\
\text { features offers low construction error }\end{array}$ & $\begin{array}{l}\text { Cone beam construction method used to make, } \\
\text { which usually give construction errors depend- } \\
\text { ing on the distance from the central slice }\end{array}$ \\
\hline $\begin{array}{l}\text { Fewer artefacts. Use of high energy and paral- } \\
\text { lel beam geometry ensures final images free of } \\
\text { geometrical and beam hardening artefacts }\end{array}$ & More artefacts: bright and dark streaks \\
\hline Costly and needing large space & Comparatively cheap and requires small space \\
\hline
\end{tabular}

$$
\text { CT number }=k \times \frac{\mu-\mu_{\mathrm{w}}}{\mu_{\mathrm{w}}},
$$

where constant (1000)

$\mathrm{X}$-rays does not fully attenuate when passing through an object thus photons of $\mathrm{X}$-rays transmitted through different layers of the object. X-ray converter called phosphor screen stops X-rays to reach to the imaging medium and finally produce visible output which is proportional to incident X-ray photons. The intensity of the transmitted photon creates different contrast in radiographs while casing protects 


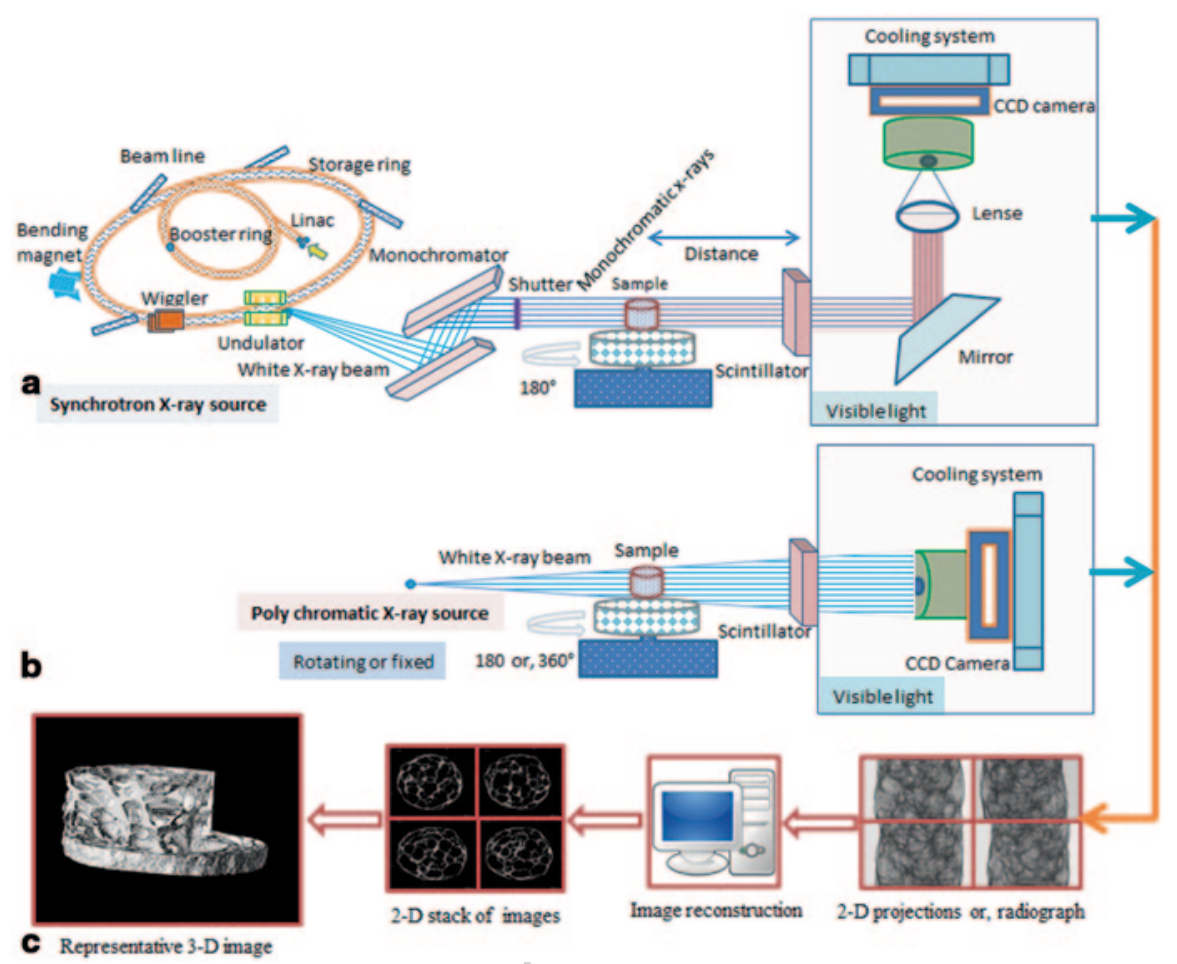

Fig. 6.2 Schematic drawing showing assembly and principle of a synchrotron and $\mathbf{b}$ desktop $X M T$ c overview of image processing

the imaging medium from other visible radiation. Hence, the obtained image produced with X-ray imaging is a transmitted image rather than reflected image which is found in conventional visible light imaging method. The quality of the X-ray image depends on the consisting element mentioned above. However, recent developments in X-ray imaging elements such as X-ray source with small focal spot, high-resolution CCD device and image intensifier make this imaging system more convenient and induced better quality.

In X-ray imaging system, X-rays come either from radio-active substance (monochromatic X-ray source) or from commonly used X-ray tube (polychromatic $\mathrm{X}$-ray beam) in which X-rays is produced by interaction between energetic electron and target atom in a vacuum place. During scanning, radiographs are produced by scanning of sample by rotating the sample over 180 or $360^{\circ}$ with a small angular increment in an axis perpendicular to the X-ray beam. Different radiographs obtained for different angular rotation differ from each other as they have different attenuation value depending on the interior structure and density. The typical X-ray parameters such as source voltage $(\mathrm{kV}$ or $\mathrm{keV}$ or $\mathrm{kVp})$ and source current $(\mu \mathrm{A}$ or $\mathrm{mA}$ ) have strong influence on the emitted X-ray photon. The lower energy photons are attenuated more readily than the higher energy photons thus CT value increases 


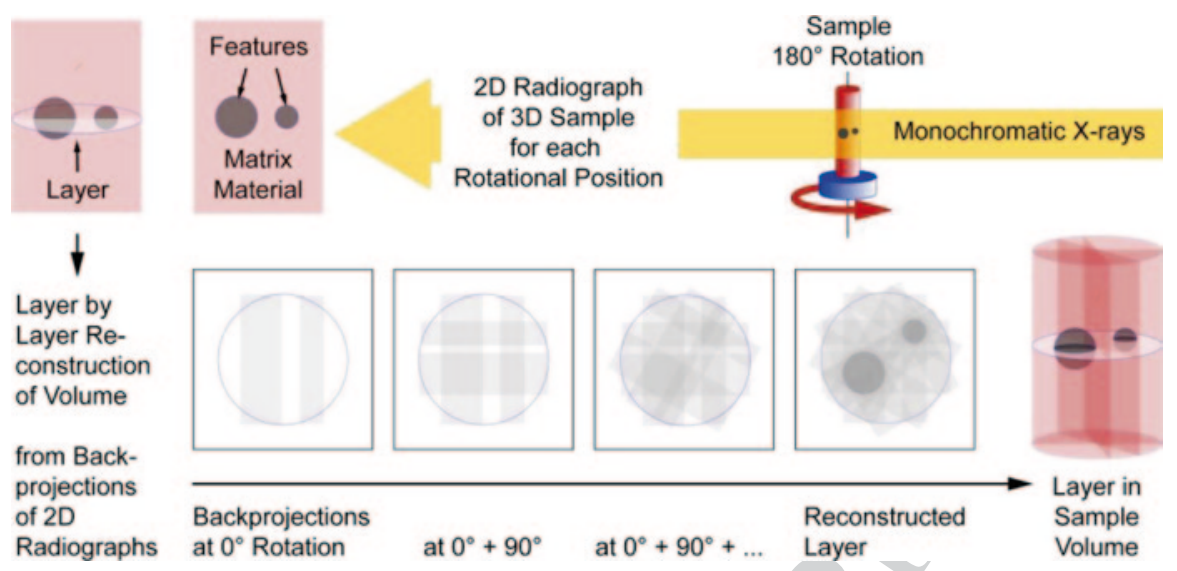

Fig. 6.3 Illustration of data acquisition and reconstruction of 3D image from 2D slices. (Adapted with permission from Betz et al. (2007))

with decreasing the source voltage. By controlling the max voltage, current and exposure time with manually adjustable hardware, XMT can produce images with varying intensity depending on the object properties. After X-ray exposure into the object, attenuated X-rays transmitted to the sensing film and form object image. Like conventional photography, high-resolution X-ray image is obtained after developing the film. The series of $2 \mathrm{D}$ radiographs are later combined using an appropriate mathematical algorithm (cone beam and back-projection software) and reconstruct a $3 \mathrm{D}$ data set consisting of a stack of 2D cross-sectional images. A series of 2D slices are obtained maintaining a constant distance in between two slices with a thickness of 1 voxel (Babin et al. 2007). Special software could be utilized for reconstruction of cross sections up to $1 \mu \mathrm{m}$ resolution for a desired orientation of the plane of cut (Trater et al. 2005). The principle of data acquisition and reconstruction is shown in Fig. 6.3. Series of multiple 2D images obtained by XMT provides more structural information than the single 2D image obtained by SEM or optical microscopy (Trater et al. 2005).

\subsection{Imaging of Cellular Solid Foods by XMT}

For successful structural characterization and quality imaging selection of right imaging parameters and accurate data, processing is important. Thus, we have selected and summarized X-ray measurement parameters used to characterize the microstructure of various cellular solid foods such as cookies, crispy bread/ roll (Table 6.2), extrudate snacks, breakfast cereals (Table 6.3) and some other cereal-based foods (Table 6.4). For cookies, X-rays generated mostly at $40-80 \mathrm{kV}$ voltage and $100-180 \mu \mathrm{m}$, while for extrudates preferred voltage and current was 20-60 kV/100-250 $\mu \mathrm{m}$ so that maximum possible features of the sample could be

Book ID: 316631_1_En ChapterID: 6 Dispatch Date: 26/10/2015 ProofNo: 1 




䒠

Book ID: 316631_1_En ChapterID: 6 Dispatch Date: 26/10/2015 ProofNo: 1 


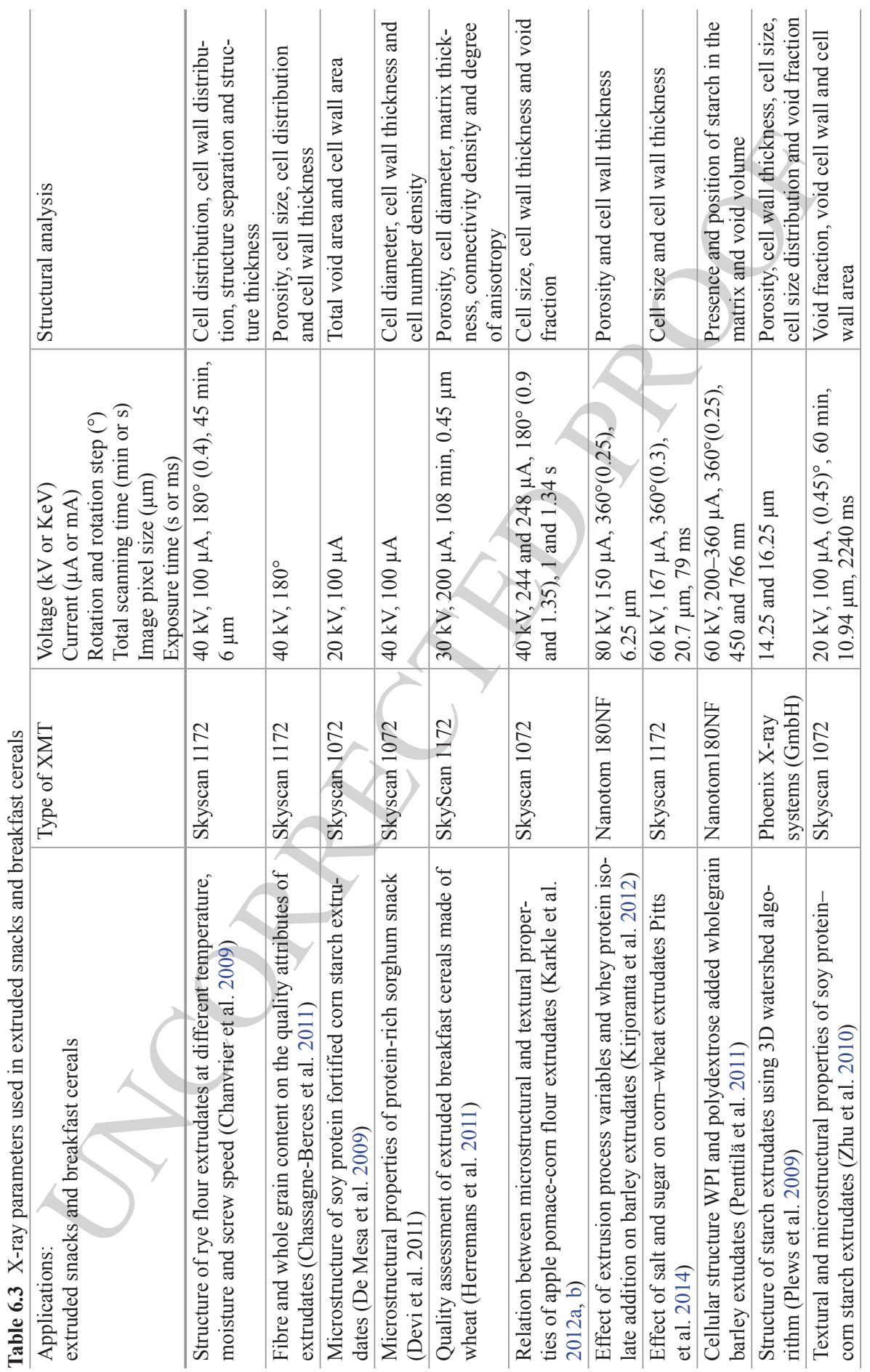

Book ID: 316631_1_En ChapterID: 6 Dispatch Date: 26/10/2015 ProofNo: 1 

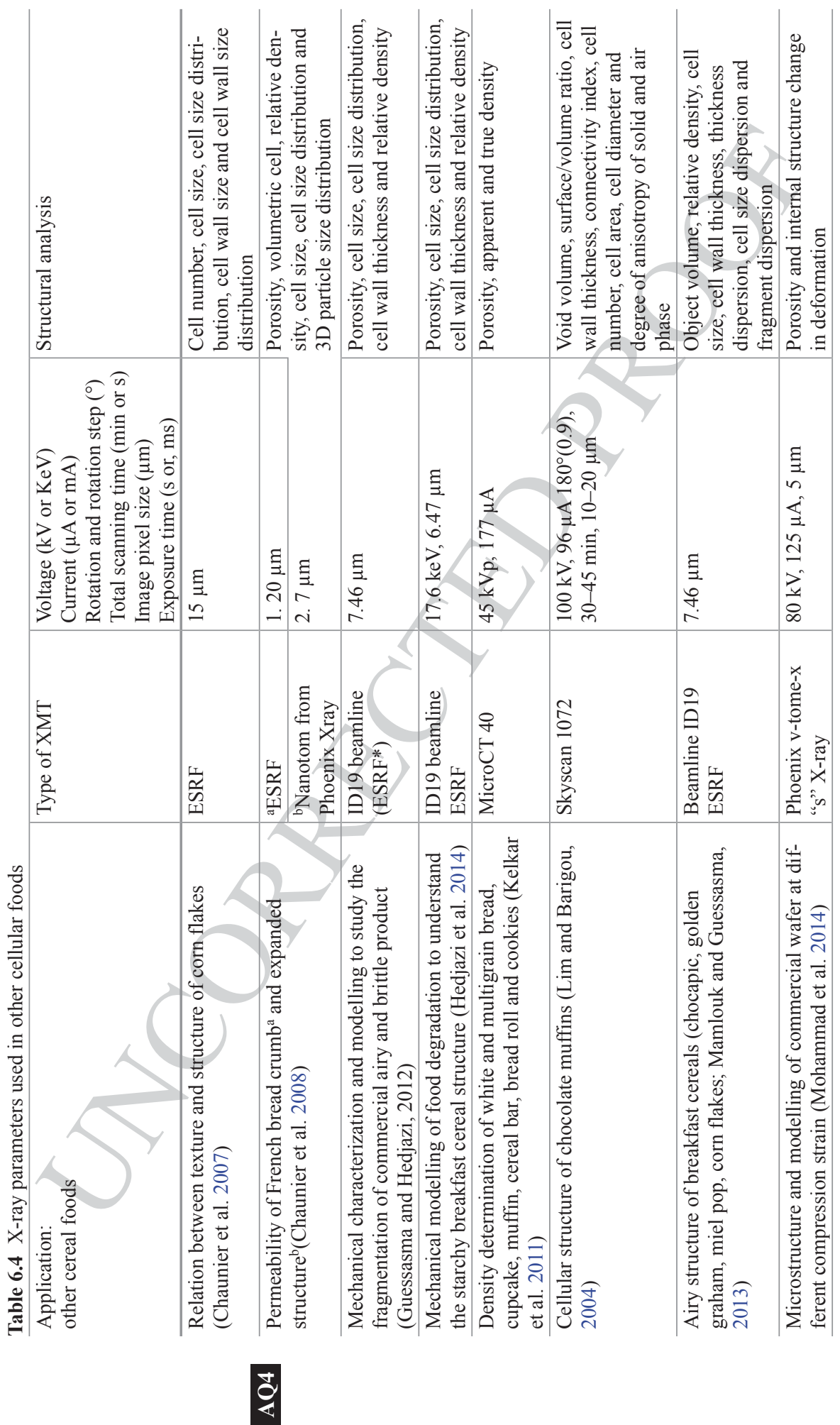

Book ID: 316631_1_En ChapterID: 6 Dispatch Date: 26/10/2015 ProofNo: 1 


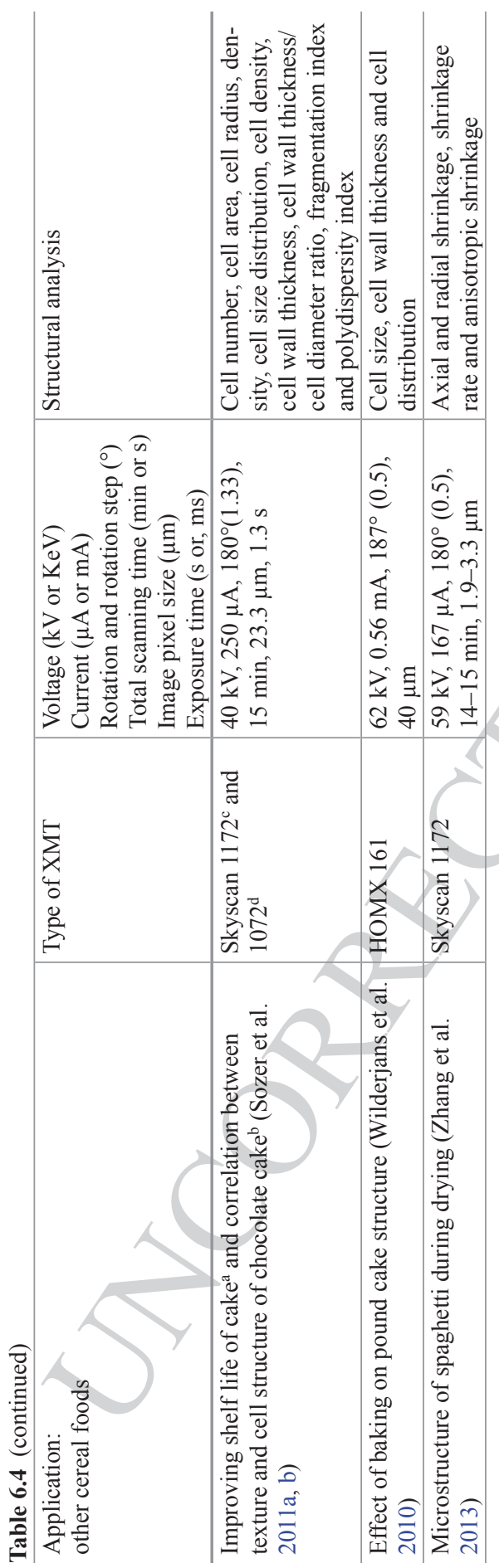

Book ID: 316631_1_En ChapterID: 6 Dispatch Date: 26/10/2015 ProofNo: 1 
captured. Generally, higher voltage and/or higher current result in saturated image (i.e., photons of X-ray are not fully attenuated to show the optimum contrast between void and solid). On the other hand, use of lower voltage and current than the required limits could result in a darker image and loss of contrast which would disable accurate image analysis (Kotwaliwale et al. 2014).

\subsubsection{Biscuits, Cookies and Crackers}

Biscuits, cookies and crackers are low-moisture baked products where they contain high levels of fat, sugar and/or salt. In biscuits and cookies, gas cells of varying size and shape exist within the starch, fat and sugar matrix (Baltsavias et al. 1999). Structure, texture and sensory properties of cookies and biscuits mainly depend on the sugar content as it incorporates air into the fat and reduce the dough viscosity (Pareyt et al. 2009). Addition of fat in cookie and biscuit recipe affects volume due to air encapsulating capacity of fat but also provides tenderness and improve flavour intensity (Maache-Rezzoug et al. 1998; Rodríguez-García et al. 2013). The effect of fat and sugar on cookie structure with XMT was first studied by Pareyt et al. (2009). Microstructural analysis of cookies of $45.5 \mathrm{~mm}$ inner diameter was done with Philips HOMX 161 (Philips, Eindhoven, Netherlands) X-ray imaging system with a voltage of $68 \mathrm{kV}$ and a current of $0.51 \mathrm{~mA}$. The samples were scanned with an angular rotation of $180^{\circ}$ and a $0.5^{\circ}$ angular increment. Total image acquisition time was $15 \mathrm{~min}$ and the resolution of resulted images was $91 \mu \mathrm{m}$. Image reconstruction was done with NRecon reconstruction software (Skyscan NV, Kontich, Belgium). Feldkamp algorithm was utilized in reconstruction software. ImageJ software was used to analyse the 3D digital images and the quantitative data were obtained. Otsu thresholding was used for segmentation (greyscale images converted to black and white) for each voxel of the image by determining the void space or solid material. To eliminate any edge effects, artefacts and cutting damage, a rectangular region of each cookie sample was extracted from the middle part of the scanned region. 3D granulometric analysis was performed using CTAn analysis software (Skyscan NV) and volumetric mean cell size, mean cell wall thickness and their distributions data were obtained. The degree of anisotropy of cells and cell walls was calculated based on mean intercept length and Eigen analysis and finally, the percentages of closed porosity were determined.

Increasing the amount of fat from 8.7 to $15.8 \%$ in the dough of sugar snap cookies increased porosity from 8.7 to $14.5 \%$. However, no effect was seen on closed structure which clearly showed that cookies, in general, had an open structure. Increasing the fat content, increased the swelling of air cells during baking which further led to an increase in mean air cell size $(643 \rightarrow 719 \mu \mathrm{m})$. Number of air cells and average cell wall anisotropy were inversely related to the fat level. Cookies with reduced fat level had less spread and small diameter. Increasing the fat content did not influence the cell wall thickness but caused a reduction in the cookie break strength. On the other hand, increased sugar levels $(17.6 \rightarrow 31.2 \%$ in the dough) 
increased porosity $(37.3 \rightarrow 46.4 \%)$, mean cell size $(399 \rightarrow 719 \mu \mathrm{m})$ and cell wall thickness $(419 \rightarrow 535 \mu \mathrm{m})$ and reduced cookie height $(10.6 \rightarrow 7.1 \mathrm{~mm})$ but no influence was observed on density and hardness (Pareyt et al. 2009). The mean cell size and cell wall thickness, and their distributions, were influenced by sugar level due to the influence of sugar on dough viscosity. Higher sugar levels in the recipe resulted in more and longer oven rise. A strong correlation between breaking strength and cell wall thickness observed particularly for sugar content varying between 18 and $26 \%$.

Soft wheat flour is generally preferred for cookie and biscuit making as it spreads faster and gives larger cookies compared to cookies from hard wheat flour possibly due to lower protein content and damaged starch levels (Pauly et al. 2013a). High levels of protein and damaged starch in the flour increased the water absorption level and thus increased dough viscosity (Gaines and Finney 1989). Wheat puroindolines (PINs) are proteins responsible for differences in wheat endosperm texture (Pauly et al. 2013b). When PINs are in their wild form, wheat kernel has a soft texture and when PINs are absent or mutated, wheat kernel has a hard texture (Pauly et al. 2013a). Semisweet biscuits were prepared from model flour consisting of starch and gluten fractions with varying PIN levels. PINs are located more at air-water interfaces (Biswas et al. 2001) and exhibit excellent foam-forming properties (Dubreil et al. 1997). Porosity and microstructure of biscuits were analysed by XMT (Bruker microCT, Kontich, Belgium) at $70 \mathrm{kV}$ and $500 \mu \mathrm{A}$. The biscuits were scanned over an interval of $0-180^{\circ}$ with 0.5 angular increments with a spatial resolution of $100 \mu \mathrm{m}$. The images were reconstructed by NRecon software (Bruker microCT, Kontich, Belgium) by using modified Feldkamp algorithm and converted into binary images by using Otsu thresholding to determine pore or solid material for each voxel in the image by utilizing ImageJ freeware. The biscuits made of higher level of PIN gave higher porosity, where porosity and matrix thickness were negatively correlated. Yang et al. (2012) studied on the impact of flavour solvent on biscuit structure, flavour stability and formation of 5-hydroxymethyl-furfural (HMF). Propylene glycol (PG) and triacetin (TA) are commonly used flavour solvents in food industry. Both PG and TA may also have an effect on the physical properties. For example, $\mathrm{PG}$ can act as a plasticizer and provide stickiness for hard candies (De Roos 2007) whereas TA gives a softer structure to chewing gum (Yang et al. 2012). The microstructure of biscuits made with TA and PG was analysed by Pheonix Nanotom NF180 X-ray CT System (GE Sensing \& Inspection Technologies $\mathrm{GmbH}$, Wunstorf, Germany) where 1440 projection images collected with a $360^{\circ}$ rotation using electron acceleration energy of $80 \mathrm{kV}$, current of $180 \mu \mathrm{A}$ and resolution of $22.5 \mu \mathrm{m}$. The obtained images were analysed by "Image J" processing software v1.44. The average pore diameter of PG biscuits was smaller than TA biscuits $(0.105$ vs. $0.11 \mathrm{~mm})$ whereas average porosity of PG biscuits was greater (49.5 vs. $45.4 \%$ ). Both flavour compound and HMF was greater in TA biscuits due to restricted diffusivity associated with lower porosity.

Multicomponent cellular solid food products with a dry shell and wet filling inside are challenging due to water migration from wet filling towards the dry shell. A good understanding of microstructure and water mobility relation will guide to 
develop moisture barrier systems which will prevent the undesirable water migration between the two different phases (Van Dalen et al. 2007a). Crackers are rather dry, thin and crisp which can be produced either leavened or unleavened. For leavened crackers the structure is mainly influenced from dough proofing time besides baking conditions and ingredients. Crackers with different porosity were made by changing the proofing time (10-130 min; Van Dalen et al. 2007b). Quantitative information related to inner structure of cracker cellular matrices was determined by 3D image analysis obtained from Skyscan 1072 XMT (Skyscan, Belgium) with a power setting of $50 \mathrm{kV}$ and $100 \mu \mathrm{A}$. Image contrast was adjusted based on absorption of X-rays by fat, carbohydrate and air within the cracker matrices. Images were acquired with a rotation of $180^{\circ}$ and $0.45^{\circ}$ step size for 40 min. Image processing and analysis was done by MATLAB and 3D yisualization was done by isosurface rendering (Amira 4.1 from Mercury Computer Systems). Moisture transport in crackers was modelled from the actual imaged samples. Air cells were segmented from the solid matrix with a manual thresholding by using a watershed transform of the Euclidean distance map of the solid material. During this process isolated air cells smaller than 40 voxels were removed. Watershed transform of the image-created boundaries which were further used to mark each air cell and the solid matrix surrounding it. The marked pore images enabled to evaluate volume, surface area and location of air cells. The relations between adjacent air cells were described by pore-to-pore properties. The network model was used to calculate the resistance between air cells. A simple model (Eq. 6.3) was developed to evaluate the point-to-point resistance in each cereal matrix. The conduction between two air cells (pores $\mathrm{i}$ and $\mathrm{j}$ ) were defined by

$$
C_{\mathrm{ij}}=\left(A d_{\mathrm{ij}}+\frac{A i_{\mathrm{ij}}}{100}\right) \times\left(\frac{1}{S A_{-} \text {pore }}\right),
$$

where $A d$ is the area between direct connected pores, $A i$ is the area of indirect connected pores and ( $S A \_$pore) is the pore surface. The point-to-point resistance was calculated by using eigenvalues and eigenfunctions of the Laplacian matrix associated with the network (Wu 2004).

Increasing the cracker proofing time increased porosity and average air cell diameter which yaried between $0.4-0.6 \mathrm{~mm}$ for proofing times $10-60 \mathrm{~min}$ and $1.2-$ $1.3 \mathrm{~mm}$ for proofing times $115-130 \mathrm{~min}$. Air cells which are more far away from each other had larger resistance than the two adjacent ones. The average pore-topore resistance of samples with large air cells was lower than the samples containing small air cells. The authors concluded that the obtained quantitative microstructural information by XMT could be utilized as an input to predict moisture diffusion.

Structural features of cellular solid matrices have an impact on liquid migration. Advanced noninvasive image analysis techniques can be utilized to develop predictive models to link structure and material properties to have better control over liquid migration. Esveld et al. (2012) developed an effective diffusivity model by utilizing cellular decomposition-based network model to study the dynamics of moisture sorption in crackers produced with different structures by varying proof- 
ing time (10-115 min). Images were obtained with a Skyscan 1072 desktop XMT system (Skyscan, Belgium) by using power setting of $50 \mathrm{kV}$ and $100 \mu \mathrm{A}$ under different rotations over $180^{\circ}$ with a step size of $0.45^{\circ}$ and a resolution of $7.8 \mu \mathrm{m}$. The water vapour transport between air cells and open pores and the sorption kinetics in the lamellae were simulated using 3D network model and then compared with experimental sorption results of cracker with distinct structures (fine vs. coarse) yet identical recipe. Predictive models had good correlation with experimental results. This study revealed that differences in relative vapour conductivity for distinct structures such as fine vs. coarse crackers (33 vs. 64\%) depends on the open surface fraction of the cell and porosity (18 vs. 22 and 66 vs. $78 \%$, fine vs. coarse, respectively). Therefore, shelf life of the cracker products could be increased based on liquid migration by decreasing the open surface fraction between the cells as it would decrease the water transport rate between the cells.

\subsubsection{Extruded Products}

Extrusion processing is a high temperature short-time method for producing cellular solid cereal foams which involves consecutive steps of mixing, shearing and formation. Operational parameters (e.g., screw speed, temperature, and feed rate) and ingredient properties have an impact on degree of expansion, micro-/macrostructure and texture. During extrusion processing irreversible physicochemical changes occur at the polymer level such as denaturation of proteins and formation of starch-lipid, protein-lipid and protein-protein complexes (Sozer and Poutanen 2011). Extruded solid foams consist of a continuous starch matrix and a discontinuous protein phase. Nevertheless, there is an increasing demand to produce appealing extruded cereal foams with high dietary fibre content yet good structural and textural properties. This is a challenging engineering task as more than $10 \%$ addition of insoluble fibre such as bran interferes with the expansion creating dense structures with hard, non-crispy textures. In this part of the chapter, we will first provide examples from the literature related to starch-based extruded foam structures and then we will present how insoluble fibre addition affects structure. The link between structure and textural properties will be demonstrated based on noninvasive XMT imaging techniques and data interpretation.

\subsubsection{Microstructure of Starch-Based Extruded Solid Foams}

Agbisit et al. (2007) determined the relation between mechanical properties (e.g., compression modulus, crushing force and stress and crispness work) and microstructure (e.g., average cell diameter, cell wall thickness and cell number density) of cellular corn starch extrudates by SkyScan 1072 (Aartselaar, Belgium) desktop XMT (20-100 kV/0-250 $\mu \mathrm{A}$; Agbisit et al. 2007). A moderate to high correlation $(r=0.48-0.81)$ was found between microstructural and mechanical properties. Gib- 
son-Ashby model was used to understand foam mechanics and to associate microstructural properties to sensory properties. Gibson-Ashby model was simplified as:

$$
\frac{t_{\text {wall }}}{l}=1.4(1-\varnothing) \frac{\rho}{\rho_{S}}
$$

where $l$ is edge length, $t_{\text {wall }}$ is wall thickness and $\rho / \rho_{\mathrm{s}}$ refers to relative density. Relative density value is less than 0.3 for true solid foams and more than 0.3 for isolated pores. Agbisit et al. (2007) suggested using a correction factor called drainage factor $(\varnothing)$ due to drainage of solids from the walls to the edges which reflects the volume fraction of the solid material present in the cell edges (Eq. 6.4).

In general, extrudates have closed air cells varying in structural architecture based on operational parameters such as the amount of water feed and screw speed. Increasing screw speed gave increased cell diameter, decreased cell number density but had no effect on cell wall thickness. Increased cell diameter and decreased cell number density gives expanded extrudates as reported by Trater et al. (2005). Mechanical properties such as crushing force and crispiness work was negatively correlated with cell diameter by $r=-0.79$ and $r=-0.81$, respectively. Mechanical properties of starch-based extrudates were dependant on the combined effect of cell wall thickness and diameter. Extrudates with higher ratio of cell wall thickness/ diameter ( $t_{\text {wall }} / D=$ thicker cell walls and smaller cell diameters) had higher compression modulus and crushing stress compared to the extrudates of lower $t_{\text {wall }} / D$ (thinner walls and larger cell diameters; Agbisit et al. 2007). Babin et al. (2007) used synchrotron (European Synchrotron Radiation Facility, F-38, Grenoble) radiation to characterize the microstructure of starchy extrudates made of amylopectin (99\%) and amylose $(70 \%)$ rich corn starch and blend of corn starch containing 47 and $24 \%$ amylose in the mixture. Extrudate samples were scanned to produce 900 (for each scan) 2D representative images with a scanning time of $10 \mathrm{~min}$. ImageJ (http://rsb.info.nih.gov/ij/) and Aphelion (ADCIS-SA, 14-France) softwares were used to analyse $3 \mathrm{D}$ images. To eliminate the edge effect, artefacts and cutting damage, VOI was selected at the centre of the sample (Fig. 6.4). Due to good contrast between void and solid phase (two distinct peaks in the picture), determination of the threshold value for segmentation was easier.

Average cell size, cell wall thickness distributions and their average volumic values were determined using 3D granulometry analysis of highly contrasted 3D image. Average cell size and average cell wall thickness of extrudates made from various maize starches (high amylose and waxy) varied between $0.2-5$ and 0.08 $63 \mathrm{~mm}$, respectively. Despite the same relative density the extrudates exhibited different microstructures determined by XMT and further data analysis. Coarse (larger cells) structures had high average cell size (inhomogeneous distribution) along with thicker cell walls which yielded less mechanical resistance.

Pore size distribution of starch-based corn flour extrudates was determined and compared by MRI and XMT imaging (Horvat et al. 2014). Extrudates with different pore sizes were produced by varying mechanical energy input (163-170-247 Wh/ kg; Fig. 6.5). Commercial cabinet cone-beam XMT ( $\mu$ CT 50, Scanco Medical AG, 

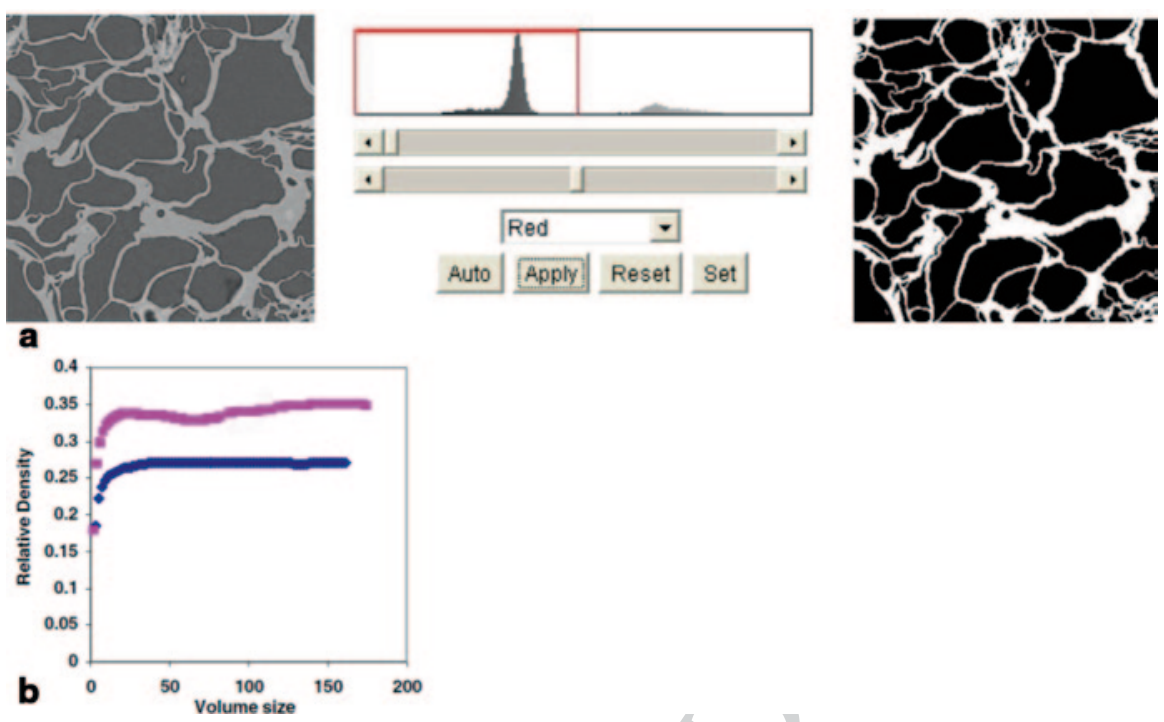

Fig. 6.4 2D. a Illustration of thresholding of $X M T$ image obtained with synchrotron facility at $E S R F$; b determination of representative volume element (RVE) for different (pink and dark blue) sample. (Adapted with permission from Babin et al. (2007))

Brüttisellen, Switzerland) was used, where cone beam X-ray generated from a $4 \mu \mathrm{m}$ focal-spot X-ray tube. Reconstructed projected images (1233 slices) of $1536 \times 1536$ matrix were obtained with a $15.05 \mathrm{~mm}$ field of view. A sample holder of inner diameter of $14 \mathrm{~mm}$ was used to place the sample inside the XMT. A cylindrical region of $\varnothing \times(14 \times 12) \mathrm{mm}$ was scanned at $9.8 \mu \mathrm{m}$ resolution (=voxel size). Scanning time $(4.5 \mathrm{~s})$ was same for all samples at $55 \mathrm{kVp}(6 \mathrm{~W})$. This study showed that starchbased extrudates could have different pore size distribution even with similar expansion indices. Mechanical properties of extruded products are influenced by both

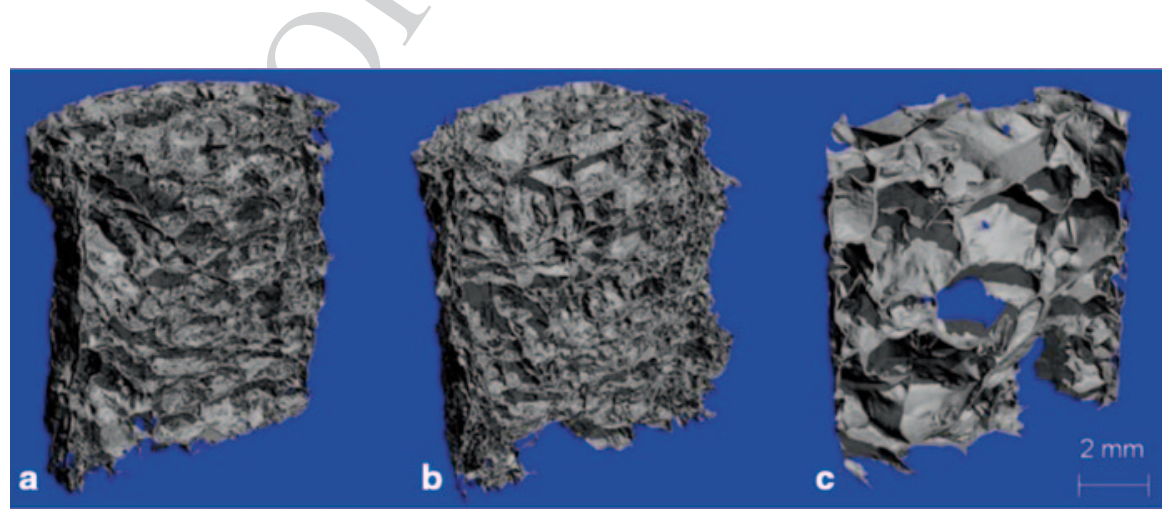

Fig. 6.5 Reconstructed $X M T$ images showing different pore structures at $S M E$ of a $247 \mathrm{Wh} / \mathrm{kg}$, b $170 \mathrm{Wh} / \mathrm{kg}$ and c $163 \mathrm{Wh} / \mathrm{kg}$. (Adapted with permission from Horvat et al. (2014)) 
expansion and porosity which can be used to predict sensory responses. Even with different spatial resolution and acquisition technique both MRI and XMT techniques showed same trends. Volume distribution ranges varies between $0.5-100 \mathrm{~mm}^{3}$ and $0.5-200 \mathrm{~mm}^{3}$ for MRI and XMT, respectively. In both techniques, largest pores and thicker cell walls were obtained with a specific mechanical energy (SME) input of $163 \mathrm{Wh} / \mathrm{kg}$. Due to better spatial resolution and limit in data processing step XMT could detect more small pores than MRI (e.g., $0.01 \mathrm{~mm}^{3}$ in XMT vs. $0.1 \mathrm{~mm}^{3}$ in MRI). In general, the cell wall thicknesses distributed between 0.01 and $0.1 \mathrm{~mm}$, a cell wall thickness of $0.025 \mathrm{~mm}$ was mainly observed. The sample extruded at $163 \mathrm{Wh} / \mathrm{kg}$ SME had thicker cell walls with a maximum at $0.04 \mathrm{~mm}$.

\subsubsection{Microstructure of Dietary Fibre Added Extruded Solid Foams}

Robin et al. (2010; 2011a, b, c; 2012a, b) made an extensive study on structural and textural effects of wheat bran supplemented extruded solid foams. The authors used 1172 desktop $\mu \mathrm{CT}$ for scanning and CTAn software for data processing (Skyscan, Kontich, Belgium). Grey level images were segmented at 40 and shrink-wrap function was used to adjust to the surface of the extruded pellets through which VOI was selected. The ratio of the volume of pores to the extrudate volume was termed as porosity. Radial expansion anisotropy was found in structures with large and fewer number of cells. Expanded structures with minimal number of cells showed less stress during rupture being less hard in texture. Stress in rupture and density was highly positively correlated. Increased amount of insoluble fibre content in the starchy matrices formed compact structure with higher number of small cells and high surface porosity due to the early burst of air cells at the die exit (Fig. 6.6) which further reduces overall expansion. Wheat flour extrudates with different added bran can have identical porosity but may differ in hardness based on bran addition level, the dimension and orientation of bran within the cell wall (Robin et al. 2012a, b).

\section{Extruded refined flour}

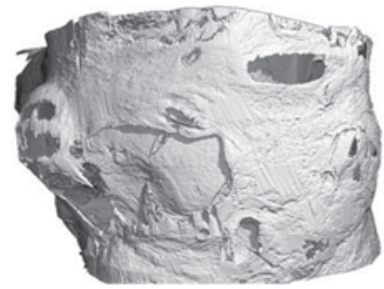

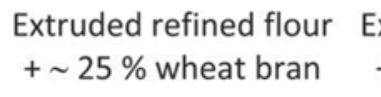

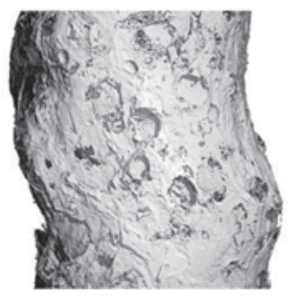

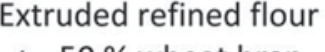

Extruded refined flour

$+\sim 50 \%$ wheat bran

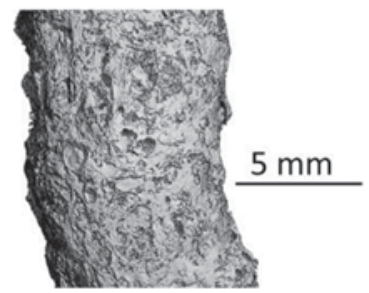

Fig. 6.6 3D XMT image of refined wheat flour-based extrudates with different levels of added wheat bran $(0,25$ and $50 \%)$ processed at same extrusion condition (screw speed of $400 \mathrm{rpm}$, $18 \%$ feed moisture and $120^{\circ} \mathrm{C}$ ). (Adapted with permission from Robin et al. (2011b); Robin et al. (2012b)) 
The effect of fibre addition on structural and mechanical properties of extruded solid foams strongly depends on the type of fibre sources. For instance, addition of $15 \%$ wheat bran into corn flour can significantly decrease the sectional expansion which is associated with increased bulk density (Robin et al. 2012b). On the other hand, addition of same level of soluble fibre such as inulin or guar gum under similar processing conditions does not alter sectional expansion but increase bulk density which is associated with reduced porosity (Robin et al. 2012b). However, Chanvrier et al. $(2013$; 2014) showed that porosity and average cell size of the extrudates decreased with increased amount of total dietary fibre content regardless of the fibre sources, while opposite trends were reported for hardness. Addition of fibre had less impact on cell wall thickness (Chanvrier et al. 2014). In these studies, two types of base recipes were produced from whole wheat flour and corn flour by adding up to $32 \%$ of wheat bran (insoluble dietary fibre) and oat bran (soluble dietary fibre) with extrusion conditions of; feed rate: $15 \mathrm{~kg} / \mathrm{h}$, temperature profile (90$135-150-160$ and $135^{\circ} \mathrm{C}$ ) and screw speed: $400 \mathrm{rpm}$. XMT imaging was done with 1172 MCT system (Brüker MicroCT, Kontich, Belgium). Image processing was done using same approaches of Robin et al. (2010). A linear increase of porosity vs. average cell size was reported for both whole wheat- and corn-based extrudates (Chanvrier et al. 2014). In general, crispiness increased with increasing number of pores in the matrix. Corn-based extrudates had lower porosity (59-90\%) compared to wheat recipe (82-92\%). The average cell sizes varied between $150-600$ and 600-1200 $\mu \mathrm{m}$ for corn- and whole wheat-based extrudates, respectively. At wide range of porosity, the number of acoustic events and total energy had a strong link with microstructural attributes (Fig. 6.7). However, when the range became narrow,

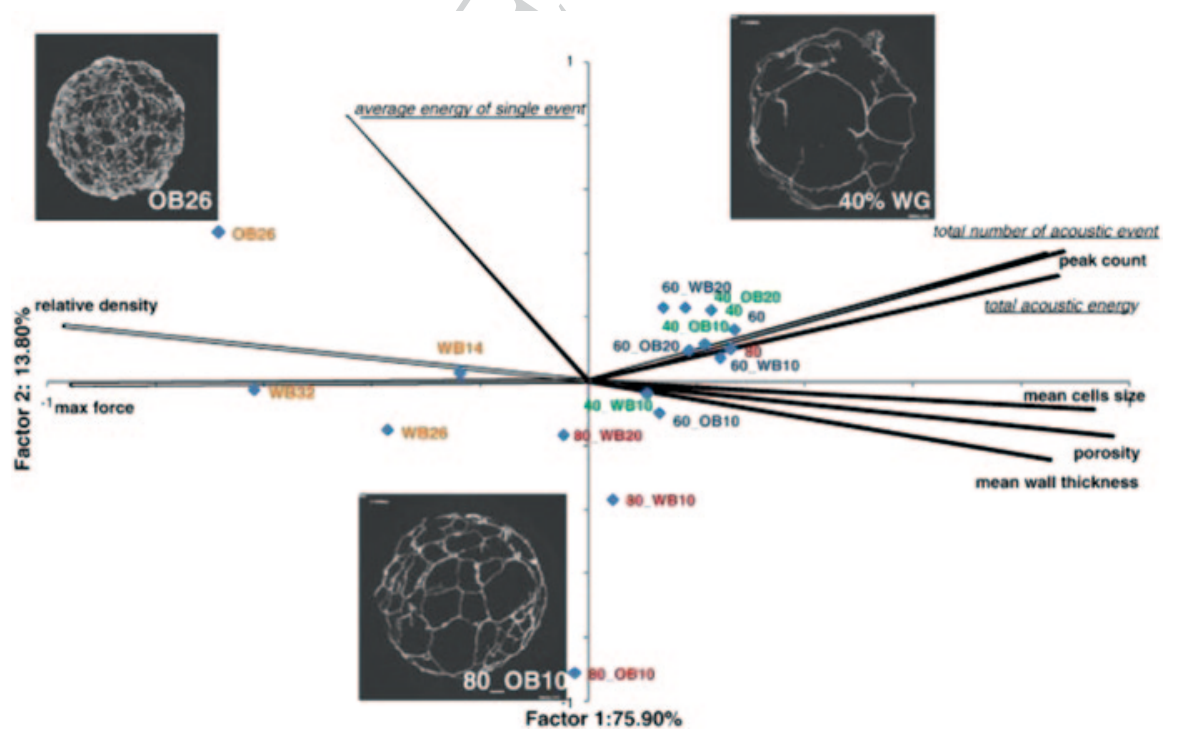

Fig. 6.7 Principal component analysis $(P C A)$ of texture, acoustic and structure data of extrudates made of corn and wheat with varying porosity between 55 and $90 \%$. XMT images of wheat- and corn-based recipe $(O B=$ oat bran; $W B=$ whole grain wheat flour). (Adapted with permission from Chanvrier et al. (2014)) 
the acoustic properties were only linked to number of peaks obtained by mechanical fracture. Therefore, crisp sound produced during the acoustic measurements depended on the organization of cell wall and their ability to break.

The effect of soluble dietary fibre; guar gum (0-10\%) addition on physical (texture, expansion, density and pasting), microstructural and starch digestibility of various flour types (potato, corn, rice and wheat) was investigated by Parada et al. (2011). Microstructural analysis was done with SkyScan1072 XMT (SkyScan, Aartselaar, Belgium) with $40 \mathrm{kV} / 100$ setting for better contrast. Extrudates (diameter: $10-18 \mathrm{~mm}$ ) were rotated $180^{\circ}$ with a step size of $0.9^{\circ}$ per image. Image reconstruction was done with volumetric reconstruction software Version 2.1, Skyscan). Filtered back-projection algorithm using a cone-beam (Feldkamp) reconstruction was utilized in reconstruction software with a reconstruction time of $4.7 \mathrm{~s} /$ cross section. After reconstruction entire cylindrical sample was captured by a set of 2D slices. VOI consisted of 30 consecutive slices from the central portion of each sample. The height of each VOI ranged between 1.6 and $7.2 \mathrm{~mm}$. Several slices of each VOI maintained a constant distance. Threshold value of 35 set to differentiate between void and solid matter in each $2 \mathrm{D}$ image. Depending on the image quality, a median rank filter was applied in a $3 \times 3$ pixel area followed by a smoothing operation. Microstructural parameters were influenced both by flour type and fibre percentage. Trabecular separation $(\mathrm{mm})$ and trabecular thickness $(\mathrm{mm})$ were affected by fibre percentage. Decreasing effect for degree of anisotropy was reported with increasing percentage of fibre in potato-, rice- and wheat-based extrudates but remained unchanged in corn-based extrudates. Increasing the fibre addition level increased the number of air cells, trabecular number $\left(\mathrm{mm}^{-1}\right)$, percent matrix volume (\%) and matrix surface density $\left(\mathrm{mm}^{-1}\right)$. Addition of guar gum increased contact area per unit volume of the extrudates and produced weaker, less hard structures. In this study, microstructure of extrudates was related to starch digestibility. The greater the contact area the greater was the accessibility of the matrix for digestive enzyme and the extrudates became more rapidly digestible.

Effect of particle size reduction on the microstructural properties of high fibre extrudates was studied by Alam et al. (2014). Extrudates were made from rye bran varying in particle size (coarse: 440; medium: 143 and fine: $28 \mu \mathrm{m}$ ) with a twin screw extruder. Rye bran has $39-48 \%$ total dietary fibre, $13-28 \%$ starch and 14-18\% protein which enables its extrusion without adding further starch. The interrelation between microstructural (porosity, $T / D$ ratio and $F I$ index), mechanical (e.g., hardness and crispiness), macro-structural (expansion, specific length and piece density) properties was studied. Decreasing the particle size (440 to $28 \mu \mathrm{m}$ ) significantly improved crispiness by increasing expansion, air cell size and porosity. Microstructural analyses were performed by Skyscan 1172 XMT device (Aartselaar, Belgium) operated at a voltage and current of $40 \mathrm{kV} / 250 \mu \mathrm{A}$ to obtain optimum contrast between void and solid matrix. Samples (triplicate of $10 \mathrm{~mm}$ radial cut) were rotated over $180^{\circ}$ with angular increment $0.7^{\circ}$ during the scanning with a pixel size of $11.65 \mu \mathrm{m}$ to obtain optimum resolution. Total scanning time of was $18 \mathrm{~min}$. NRecon reconstruction software (v. 1.6.6) used to convert 2D cross-section images into $3 \mathrm{D}$ image. Beam hardening correction was set to $40 \%$ to minimize artefacts. 


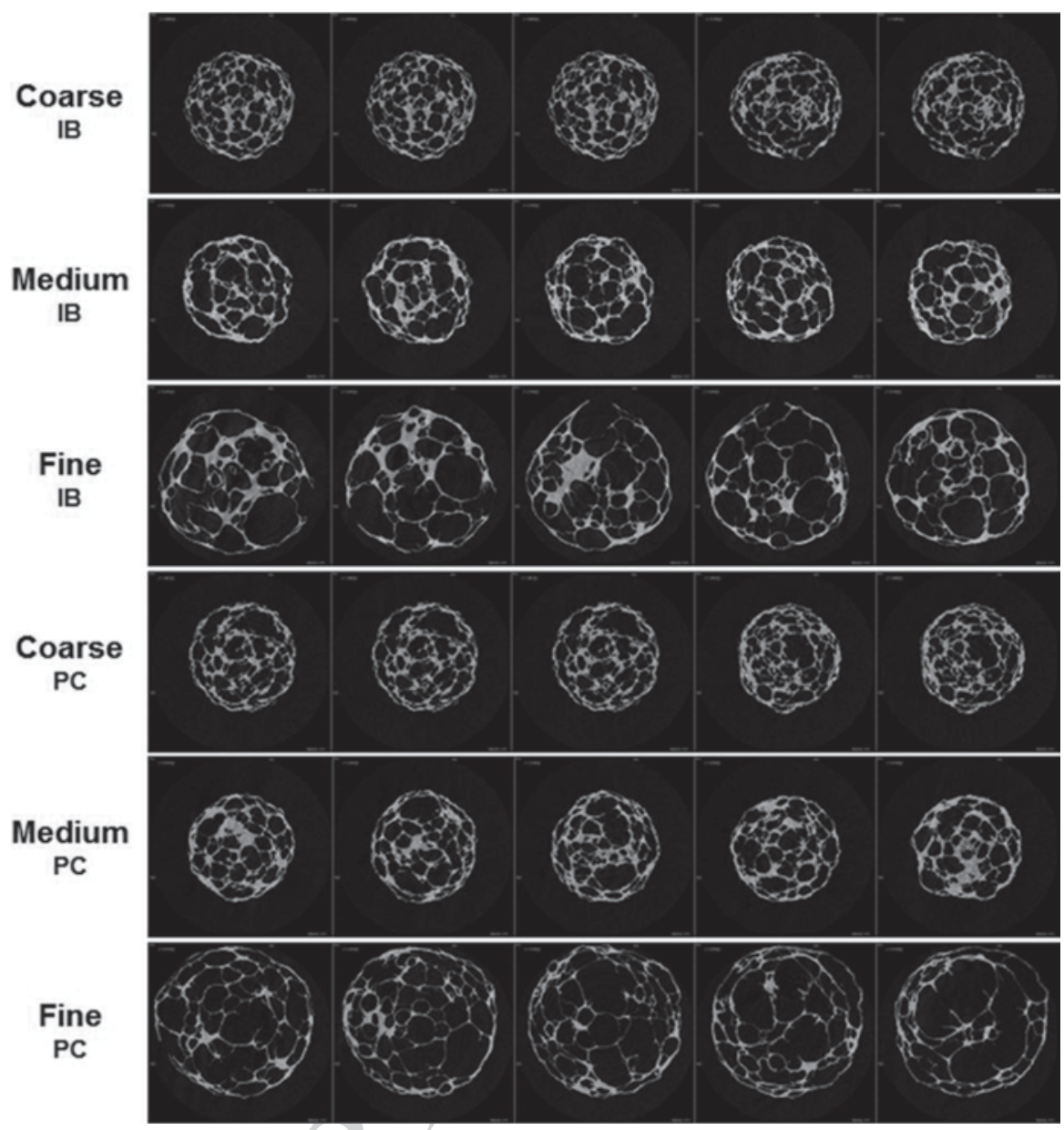

Fig. 6.8 2D XMT images of rye bran (particle sizes of coarse: $440 \mu \mathrm{m}$, medium: $143 \mu \mathrm{m}$ and fine: $28 \mu \mathrm{m})$ extrudates processed with $17 \%$ feed moisture in two different hydration regimens $(I B=\mathrm{In}$ barrel-water feed and $P C=$ Preconditioning) at a screw speed of $500 \mathrm{rpm}$ at $130^{\circ} \mathrm{C}$. (Adapted with permission from Alam et al. (2014))

CTAn software (v. 1.12, Skyscan, Belgium) was used to calculate the microstructural parameters.

It is clear from the representative images (Fig. 6.8) that particle reduction increased the average cell diameter (ranged between 0.49 and $1.17 \mathrm{~mm}$; highest for fine bran) and expansion rate. Reducing particle size from 440 to $28 \mu \mathrm{m}$ increased the porosity from 64.4 to $83.9 \%$. Early rupture of the precursor air cells caused more small air cells in coarse- and medium-particle-sized rye bran extrudates $(\approx 2800$ $4000)$ as compared to fine extrudates $(\approx 1000)$. The effect of particle size was more 548 profound on cell diameter than on cell wall thickness. Microstructural parameters 549 of coarse and medium-sized bran extrudates were not affected by hydration regimen 


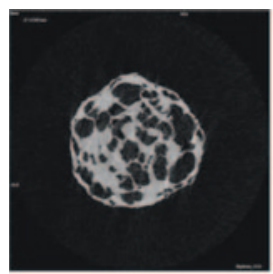

1. WF $100 \%$

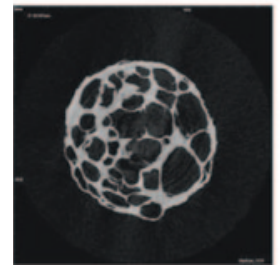

5. $E F+E H-O B C 10 \%$

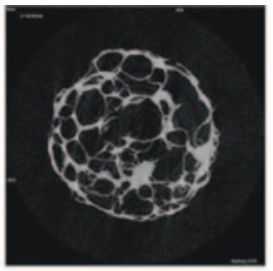

2. EF $100 \%$

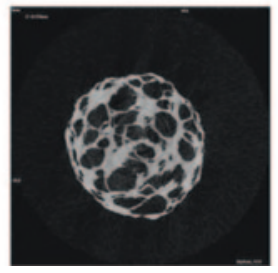

6. $E F+W I S-O B C 10 \%$

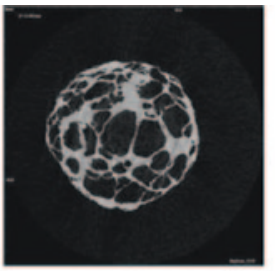

3. $E F+O B C 10 \%$

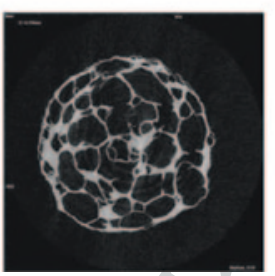

7. $E F+W S-O B C 10 \%$

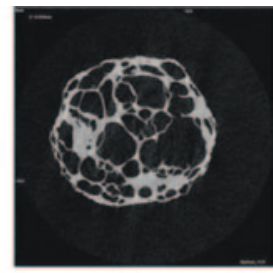

4. $E F+U F-O B C 10 \%$

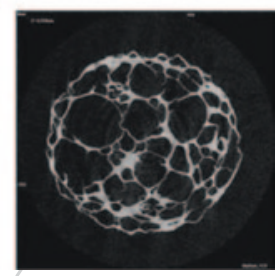

8. $E F+W S-O B C 20 \%$
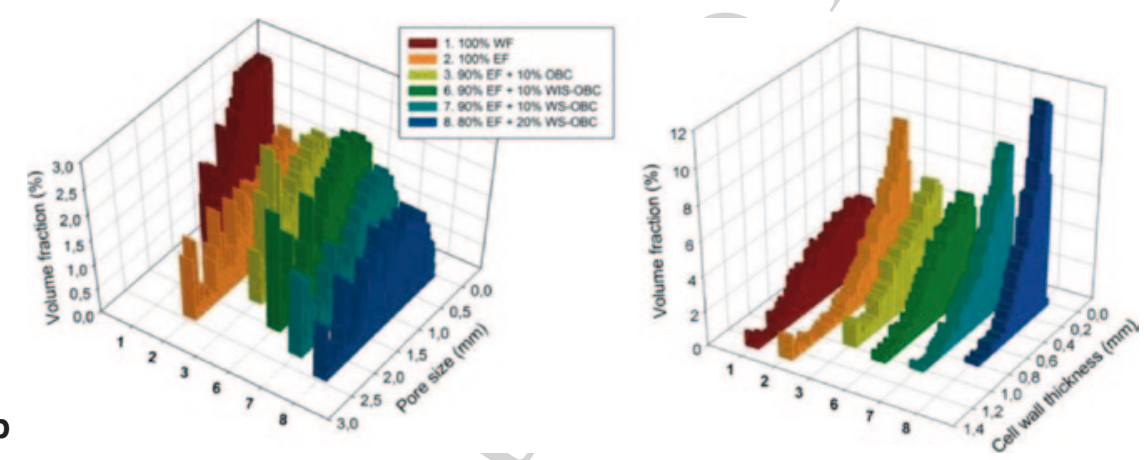

Fig. 6.9 a 2D $X M T$ cross-section images of extrudates made of different oat ingredients: $W F$ wholegrain oat flour, $E F$ endosperm oat flour, $O B C$ oat bran concentrate, $U F$ ultra-fine, $E H$ enzyme hydrolysed, WIS water insoluble, WS water soluble. b Pore size and cell wall thickness distributions of the oat extrudates. Data of samples 4 (EF+UF-OBC $10 \%)$ and 5 (EF+EH-OBC $10 \%)$ exhibited similar results to that of sample $3(\mathrm{EF}+\mathrm{OBC} 10 \%)$ thus not shown in the plot. (Adapted with permission from Sibakov et al. (2014))

\section{AQ6}

but preconditioning resulted increased porosity by $6 \%$ and decreased $T / D$ ratio by $50 \%$. Higher connectivity of the pores was confirmed by low fragmentation index values $(-0.8$ and $-4.5 \mathrm{~L} \mathrm{~mm})$.

Sibakov et al. (2014) studied the effect of differently treated oat bran concentrate (OBC) into $90 \%$ defatted oat endosperm flour (EF) extrudates made by twin screw extruder. XMT analyses were performed using similar protocol as of Alam et al. (2014). Representative XMT images are shown in Fig. 6.9a. They reported that extrudates made of untreated OBC $(213 \mu \mathrm{m})$ had lower porosity $(65 \%$ vs. 69 and $71 \%)$ compared to the extrudates made of fine $(32 \mu \mathrm{m})$ and enzyme-hydrolysed OBC $(111 \mu \mathrm{m})$. Addition of $10 \%$ OBC increased $(0.34-0.42$ vs. $0.32 \mathrm{~mm})$ the cell wall thickness compared to $100 \%$ EF. The $10 \%$ addition of water insoluble OBC 
$(70 \mu \mathrm{m})$ into EF reduced the porosity from 75 to $59 \%$, while the addition of $10 \%$ water soluble OBC $(37 \mu \mathrm{m})$ did not affect the porosity. However, further increase in water-soluble OBC increased the porosity and for $20 \%$ addition level porosity reported to be $81 \%$. Moreover, a decreasing trend was observed for average cell wall thickness when increasing the content of water-soluble OBC. The number of small pores was higher in case of water-insoluble OBC added extrudates than that of water-soluble OBC extrudates (10 20\%). Thick cell walls with small pore sizes were reported for all treated OBC extrudates except $20 \%$ water-soluble OBC added extrudates. Hundred percent whole grain oat flour extrudates had narrowest pore size distribution with small porosity together with large cell wall distribution including mostly thick cell walls. However, extrudates with $20 \%$ water-soluble OBC had wider pore size distribution with larger pores and thinner cell walls (Fig. 6.9b). Hence, the microstructural properties of oat bran added endosperm oat flour extrudates depend mainly on the solubility of DF.

\subsubsection{Microstructure of Protein-Enriched Extruded Solid Foams}

Microstructural properties of corn starch extrudates enriched with whey protein isolate (WPI; 0, 6, 12 and 18\%) processed at two different water feed (23 and 27\%) levels were determined with XMT (Cheng et al. 2007). Increasing the level of WPI increased the foaming effect thus increased the cell density. In general, incorporation of protein gave greater number of smaller cells with thinner cell wall, regardless of water addition level. The effect of water feed on microstructural properties such as average cell diameter, average cell wall thickness and cell number density was not consistent throughout the experiments except cell wall thickness. Cell wall thickness increased from $(0.04-0.07)$ to $(0.09-0.27 \mathrm{~mm})$ by increasing amount of water feed from 23 to $27 \%$ which further increased hardness (Cheng et al. 2007). Cho and Rizvi (2009) used supercritical fluid extrusion (SCFX) technology for pregelatinized corn-starch-based extrudates supplemented with WPI $(0,3,6,12$, and 18\%). A desktop XMT (Model 1072, 20-100 kV/0-250 $\mu$ A, SkyScan, Belgium) used to analyse microstructure by setting the voltage $40 \mathrm{kV}$ and resolution $100 \mu \mathrm{A}$. Skyscan software was used to produce a set of 2D images to capture whole sample. Later the set of 2D images was partitioned to get the VOI, which consisted of 15 consecutive 2D slices with a constant distance between the slices. Image analysis was performed using one fourth of the cross-sectional area of each $2 \mathrm{D}$ slices. Cell perimeter, solid and void areas were calculated using a threshold value of 35, from each slices. Scion Image for Windows (Scion Corporation, MD) was used for the calculation. The analysed microstructural parameters were: average cell diameter, cell wall thickness, void fraction, polydispersity index, cell density per unit total extrudate volume, and cell number density per unit solid volume.

Increasing the level of WPI in SCFX extrudates resulted in lower cell density and reduced volumetric expansion as denaturation of WPI reduced melt viscosity. At highest level of WPI (18 wt $\%)$ and $\mathrm{SC}-\mathrm{CO}_{2}$ level $(0.75 \mathrm{wt} \%)$, the average cell size reduced $(600 \mu \mathrm{m} \rightarrow 310 \mu \mathrm{m})$ exceptionally due to heterogeneous nucleation 
depending on the blowing agent and on the feed formulation. The cell number density per unit total extrudate volume and cell number density per unit solid volume both decreased with the increasing amount of WPI except $18 \%$ WPI at $0.75 \mathrm{wt} \%$ $\mathrm{SC}-\mathrm{CO}_{2}$. On the other hand, the cell number density increased with the increasing amount of $\mathrm{SC}-\mathrm{CO}_{2}$ for each WPI level due to the increased number of gas nucleation.

\subsection{Summary and Conclusions}

The successful use of XMT in other fields of science (e.g., medical, agricultural, biological and material science) has led its further application in food structure characterization. Cellular solid structures have great impact on sensory properties and associated with also textural-mechanical properties. XMT is able to present rigorous quantitative information related to cellular architecture of solid foods such as cell size and distribution, cell wall thickness, cell connectedness and porosity both in 2D and 3D. The accurate microstructural characterization of cellular solid foods would also help food engineers and scientists to understand and develop links between structure-mechanical-sensory properties. Based on these and the use of numerical simulation technologies together with modelling approaches can be used to design novel food structures and textures. Furthermore, the noninvasive XMT technology does not require tedious sample preparation methods compared to other microscopy technologies such as light microscopy or confocal scanning light microscopy. The continuous development in data processing and equipment manufacturing technologies will enable the use of XMT technology for in-line or on-line food structure analysis during processing.

\section{References}

Agbisit R, Alavi S, Cheng E, Herald T, Trater A (2007) Relationships between microstructure and mechanical properties of cellular cornstarch extrudates. J Texture Stud 38(2):199-219

Alam SA, Järvinen J, Kirjoranta S, Jouppila K, Poutanen K, Sozer N (2014) Influence of particle size reduction on structural and mechanical properties of extruded rye bran. Food Bioprocess Tech 7:2121-2133

Babin P, Della Valle G, Dendievel R, Lourdin D, Salvo L (2007) X-ray tomography study of the cellular structure of extruded starches and its relations with expansion phenomenon and foam mechanical properties. Carbohyd Polym 68(2):329-340

Baltsavias A, Jurgens A, Van Vliet T (1999) Fracture properties of short-dough biscuits: effect of composition. J Cereal Sci 29(3):235-244

Barigou M, Douaire M, Morris V, Groves K (2013) X-ray micro-computed tomography for resolving food microstructures. In: Morris VJ, Groves K (eds) Food microstructures: microscopy, measurement and modelling. Woodhead, Cambridge, p 246-272

Betz O, Wegst U, Weide D, Heethoff M, Helfen L, LEE W, Cloetens P (2007) Imaging applications of synchrotron X-ray phase-contrast microtomography in biological morphology and 
biomaterials science. I. General aspects of the technique and its advantages in the analysis of millimetre-sized arthropod structure. J Microsc 227(1):51-71

Bhatnagar S, Hanna MA (1996) Effect of talc on properties of cornstarch extrudates. Starch-Starke 48(3):94-101

Biswas S, Dubreil L, Marion D (2001) Interfacial behavior of wheat puroindolines: study of adsorption at the air-water interface from surface tension measurement using Wilhelmy plate method. J Colloid Interf Sci 244(2):245-253

Chanvrier H, Gumy J, Blank I (2009) Food solid foams made from cereals: assessment of the structure of extruded rice by X-ray tomography. Paper presented at the SkyScan user meeting, Bruker microCT, Ghent, 22-24 April 2009

Chanvrier H, Desbois F, Perotti F, Salzmann C, Chassagne S, Gumy J, Blank I (2013) Starch-based extruded cereals enriched in fibers: a behavior of composite solid foams. Carbohyd Polym 98(1):842-853

Chanvrier H, Jakubczyk E, Gondek E, Gumy J (2014) Insights into the texture of extruded cereals: structure and acoustic properties. Innov Food Sci Emerg 24:61-68

Chassagne-Berces S, Leitner M, Melado A, Barreiro P, Correa EC, Blank I, Gumy J, Chanvrier $\mathrm{H}$ (2011) Effect of fibers and whole grain content on quality attributes of extruded cereals. Procedia Food Sci 1:17-23

Chaunier L, Della Valle G, Lourdin D (2007) Relationships between texture, mechanical properties and structure of cornflakes. Food Res Int 40(4):493-503

Chaunier L, Chrusciel L, Delisée C, Della Valle G, Malvestio J (2008) Permeability and expanded structure of baked products crumbs. Food Biophys 3(4):344-351

Cheng E, Alavi S, Pearson T, Agbisit R (2007) Mechanical-acoustic and sensory evaluations of cornstarch-whey protein isolate extrudates. J Texture Stud 38(4):473-498

Chevallier S, Réguerre A, Bail A L, Della Valle G (2014) Determining the cellular structure of two cereal food foams by X-ray micro-tomography. Food Biophys 9:219-228

Cho K, Rizvi S (2009) 3D microstructure of supercritical fluid extrudates I: melt rheology and microstructure formation. Food Res Int 42(5):595-602

Curry TS, Dowdey JE, Murry RC Jr (eds) (1990) Christensen's physics of diagnostic radiology. Lippincott Williams \& Wilkins, Pennsylvania

De Mesa NJE, Alavi S, Singh N, Shi Y, Dogan H, Sang Y (2009) Soy protein-fortified expanded extrudates: baseline study using normal corn starch. J Food Eng 90(2):262-270

De Roos KB (2007) Selecting the right flavourings for a food product. In: Taylor AJ, Hort J (eds) Modifying flavour in food. Woodland, Cambridge, p 243-273

Devi NL, Shobha S, Tang X, Shaur SA, Dogan H, Alavi S (2013) Development of protein-rich sorghum-based expanded snacks using extrusion technology. Int J Food Prop 16(2):263-276

Dubreil L, Compoint J, Marion D (1997) Interaction of puroindolines with wheat flour polar lipids determines their foaming properties. J Agr Food Chem 45(1):108-116

Esveld D, van der Sman R, Witek M, Windt C, van As H, van Duynhoven J, Meinders M (2012) Effect of morphology on water sorption in cellular solid foods. Part II: sorption in cereal crackers. J Food Eng 109(2):311-320

European Synchrotron Radiation Facility-The European Synchrotron (ESRF) (2015) What is synchrotron? http://www.esrf.eu/about/synchrotron-science/synchrotron. Accessed 05 Feb 2015

Frisullo P, Conte A, Del Nobile M (2010) A novel approach to study biscuits and breadsticks using X-Ray computed tomography. J Food Sci 75(6):E353-E358

Gaines C, Finney P (1989) Effects of selected commercial enzymes on cookie spread and cookie dough consistency. Cereal Chem 66:73-78

Gondek E, Jakubczyk E, Herremans E, Verlinden B, Hertog M, Vandendriessche T, Verboven P, Antoniuk A, Bongaers E, Estrade P (2013) Acoustic, mechanical and microstructural properties of extruded crisp bread. J Cereal Sci 58(1):132-139

Hedjazi L, Martin C, Guessasma S, Della Valle G, Dendievel R (2014) Experimental investigation and discrete simulation of fragmentation in expanded breakfast cereals. Food Res Int 55:28-36

Herremans E, Chassagne-Berces S, Chanvrier H, Atoniuk A, Kusztal Z, Bongaers E, Verlinden BE, Jakubczyk E, Estrade P, Verboven P, Nicolaï B (2011). Possibilities of X-ray nano-CT for 
internal quality assessment of food products. Paper presented at the 11th International Congress on Engineering and Food (ICEF), Athens, 22-26 May 2011

Hicsasmaz Z, Clayton JT (1992) Characterization of the pore structure of starch based food materials. Food Struct 11(2):115-132

Horvat M, Guthausen G, Tepper P, Falco L, Schuchmann HP (2014) Non-destructive, quantitative characterization of extruded starch-based products by magnetic resonance imaging and X-ray microtomography. J Food Eng 124:122-127

Jones D, Chinnaswamy R, Tan Y, Hanna M (2000) Physiochemical properties of ready-to-eat breakfast cereals. Cereal Food World 45(4):164-168

Karkle EL, Alavi S, Dogan H (2012a) Cellular architecture and its relationship with mechanical properties in expanded extrudates containing apple pomace. Food Res Int 46(1):10-21

Karkle EL, Keller L, Dogan H, Alavi S (2012b) Matrix transformation in fiber-added extruded products: impact of different hydration regimens on texture, microstructure and digestibility. J Food Eng 108(1):171-182

Kelkar S, Stella S, Boushey C, Okos M (2011) Developing novel 3D measurement techniques and prediction method for food density determination. Procedia Food Sci 1:483-491

Kiani H, Sun D (2011) Water crystallization and its importance to freezing of foods: a review. Trends Food Sci Tech 22(8):407-426

Kirjoranta S, Solala K, Suuronen J, Penttilä P, Peura M, Serimaa R, Tenkanen M, Jouppila K (2012) Effects of process variables and addition of polydextrose and whey protein isolate on the properties of barley extrudates. Int J Food Sci Tech 47(6):1165-1175

Kotwaliwale N, Kalne A, Singh K (2010) Radiography, CT and MRI. In: Jha SN (ed) Nondestructive evaluation of food quality- theory and practice. Springer, Berlin, pp 101-140

Kotwaliwale N, Singh K, Kalne A, Jha SN, Seth N, Kar A (2014) X-ray imaging methods for internal quality evaluation of agricultural produce. J Food Sci Tech 51(1):1-15

Lassoued N, Babin P, Della Valle G, Devaux M, Réguerre A (2007) Granulometry of bread crumb grain: contributions of 2D and 3D image analysis at different scale. Food Res Int 40(8):1087-1097

Lim KS, Barigou M (2004) X-ray micro-computed tomography of cellular food products. Food Res Int 37(10):1001-1012

Maache-Rezzoug Z, Bouvier J, Allaf K, Patras C (1998) Effect of principal ingredients on rheological behaviour of biscuit dough and on quality of biscuits. J Food Eng 35(1):23-42

Mamlouk H, Guessasma S (2013) Finite element simulation of the compression behaviour of airy breakfast cereals. Innov Food Sci Emerg 19:190-203

Mohammed I, Charalambides M, Williams J, Rasburn J (2014) Modelling the microstructural evolution and fracture of a brittle confectionery wafer in compression. Innov Food Sci Emerg 24:48-60

Parada J, Aguilera JM, Brennan C (2011) Effect of guar gum content on some physical and nutritional properties of extruded products. J Food Eng 103(3):324-332

Pareyt B, Talhaoui F, Kerckhofs G, Brijs K, Goesaert H, Wevers M, Delcour JA (2009) The role of sugar and fat in sugar-snap cookies: structural and textural properties. J Food Eng 90(3):400408

Pauly A, Pareyt B, Lambrecht MA, Fierens E, Delcour JA (2013a) Impact of puroindolines on semisweet biscuit quality: a fractionation-reconstitution approach. Cereal Chem 90(6):564-571

Pauly A, Pareyt B, Fierens E, Delcour JA (2013b) Wheat (Triticum aestivum L. and T. turgidum L. ssp. durum) kernel hardness: i. Current view on the role of puroindolines and polar lipids. Compr Rev Food Sci F 12(4):413-426

Penttilä PA, Suuronen J, Kirjoranta S, Peura M, Jouppila K, Tenkanen M, Serimaa R (2011) X-ray characterization of starch-based solid foams. J Mater Sci 46(10):3470-3479

Pitts KF, Favaro J, Austin P, Day L (2014) Co-effect of salt and sugar on extrusion processing, rheology, structure and fracture mechanical properties of wheat-corn blend. J Food Eng 127:58-66

Plews AG, Atkinson A, McGrane S (2009) Discriminating structural characteristics of starch extrudates through X-ray micro-tomography using a 3-D watershed algorithm. Int J Food Eng 5(1). doi:10.2202/1556-3758.1513 
Primo-Martín C, Van Dalen G, Meinders M, Don A, Hamer R, Van Vliet T (2010) Bread crispness and morphology can be controlled by proving conditions. Food Res Int 43(1):207-217

Robin F, Engmann J, Pineau N, Chanvrier H, Bovet N, DellaValle G (2010) Extrusion, structure and mechanical properties of complex starchy foams. J Food Eng 98(1):19-27

Robin F, Dubois C, Curti D, Schuchmann HP, Palzer S (2011a) Effect of wheat bran on the mechanical properties of extruded starchy foams. Food Res Int 44(9):2880-2888

Robin F, Dubois C, Pineau N, Schuchmann HP, Palzer S (2011b) Expansion mechanism of extruded foams supplemented with wheat bran. J Food Eng 107(1):80-89

Robin F, Dubois C, Schuchmann HP, Palzer S (2011c) Supplementation of extruded foams with wheat bran: effect on textural properties. Procedia Food Sci 1:505-512

Robin F, Dubois C, Pineau N, Labat E, Théoduloz C, Curti D (2012a) Process, structure and texture of extruded whole wheat. J Cereal Sci 56(2):358-366

Robin F, Schuchmann HP, Palzer S (2012b) Dietary fiber in extruded cereals: limitations and opportunities. Trends Food Sci Tech 28(1):23-32

Rodríguez-García J, Laguna L, Puig A, Salvador A, Hernando I (2013) Effect of fat replacement by inulin on textural and structural properties of short dough biscuits. Food Bioprocess Tech 6(10):2739-2750

Sibakov J, Kirjoranta S, Alam SA, Kokkonen H, Jurvelin J, Jouppila K, Poutanen K, Sozer N (2014) Effects of native and modified oat bran on extrudates made of defatted oats. Food Bioprocess Tech. doi:10.1007/s11947-014-1425-4

Sozer N, Poutanen K (2013) Fibre in extruded food products. In: Delcour JA, Poutanen K (eds) Fibre-rich and wholegrain foods - improving quality. Woodland, Cambridge, p 226-272

Sozer N, Bruins R, Dietzel C, Franke W, Kokini JL (2011a) Improvement of shelf life stability of cakes. J Food Quality 34(3):151-162

Sozer N, Dogan H, Kokini JL (2011b) Textural properties and their correlation to cell structure in porous food materials. J Agr Food Chem 59(5):1498-1507

Trater A, Alavi S, Rizvi S (2005) Use of non-invasive X-ray microtomography for characterizing microstructure of extruded biopolymer foams. Food Res Int 38(6):709-719

Van Dalen G, Nootenboom P, Van Vliet LJ, Voortman L, Esveld E (2007a) 3D imaging, analysis and modelling of porous cereal products using X-ray microtomography. Image Anal Stereol 26:169-177

Van Dalen G, Nootenboom P, Van Vliet LJ (2007b) 3D Imaging and analysis of porous cereal products using X-ray microtomography. Paper presented at the 12th International Congress for Stereology (ICS XII), Saint-Etienne, 30 August-7 September

Vidal FP, Letang JM, Peix G, Cloetens P (2005) Investigation of artefact sources in synchrotron microtomography via virtual X-ray imaging. Nucl Instrum Meth B 234(3):333-348

Voogt JA, Hirte A, Meinders MB (2011) Predictive model to describe water migration in cellular solid foods during storage. J Sci Food Agr 91(14):2537-2543

Wilderjans E, Kerckhofs G, Lagrain B, Brijs K, Wevers M, Delcour J (2010) Baking gradients cause heterogeneity in starch and proteins in pound cake. Cereal Chem 87(5):475-480

Wu F (2004) Theory of resistor networks: the two-point resistance. J Phys A-Math Gen 37(26):6653

Yang N, Fisk ID, Linforth R, Brown K, Walsh S, Mooney S, Sturrock C, Hort J (2012) Impact of flavour solvent on biscuit micro-structure as measured by X-ray micro-computed tomography and the distribution of vanillin and HMF (HPLC). Eur Food Res Technol 235(6):1083-1091

Zhang L, Nishizu T, Kishigami H, Kato A, Goto K (2013) Measurement of internal shrinkage distribution in spaghetti during drying by X-ray $\mu$ CT. Food Res Int 51(1):180-187

Zhu L, Shukri R, De Mesa-Stonestreet NJ, Alavi S, Dogan H, Shi Y (2010) Mechanical and microstructural properties of soy protein-high amylose corn starch extrudates in relation to physiochemical changes of starch during extrusion. J Food Eng 100(2):232-238 